\title{
PAVING THE WAY TO SMART SUSTAINABLE CITIES: TRANSFORMATION MODELS AND CHALLENGES
}

\section{Maysoun Ibrahim}

Faculty of Science, Department of Mathematics and Computer Science, Beirut Arab University, Beirut, Lebanon

\section{Carl Adams}

School of Computing, University of Portsmouth, Portsmouth, United Kingdom

\section{Ali El-Zaart}

Faculty of Science, Department of Mathematics and Computer Science, Beirut Arab University, Beirut, Lebanon

\begin{abstract}
Rapid urbanization and globalization make the move toward Smart Sustainable Cities (SSC) a must. Achieving successful transformation towards SSCs constitutes a significant challenge for policy makers. One area that is not well covered in the literature is the application of SSCs in specific regions, such as the Arab region. This paper draws upon examples of SSCs initiatives and existing SSC transformation frameworks to more fully articulate the challenges of achieving successful SSC projects across the Arab region. One of the interesting emergent themes is the emergence of two main approaches to SSCs transformation, Brownfield and Greenfield approaches.
\end{abstract}

Keyword: Smart Sustainable City; transformation framework; Arab region; challenges; development.

\section{INTRODUCTION}

Cities have a significant impact on the development level of a country. They provide a platform for people to live and work, establish services and operations for citizens in a wide range of ways and facilitate a close contact between local government officials and citizens. With globalization and the move towards economic, social, environmental and technological development, cities are now competing with each other to attract investments and knowledge workers and promote themselves as smart,

Manuscript first received/Recebido em: 05/07/2015 Manuscript accepted/Aprovado em: 09/11/2015

Address for correspondence / Endereço para correspondência

Maysoun Ibrahim, Faculty of Science, Department of Mathematics and Computer Science, Beirut Arab University, Fouad Arslan Street, Beirut, Lebanon E-mail: maisonib@ hotmail.com

Carl Adams, School of Computing, University of Portsmouth, Portsmouth, United Kingdom E-mail: carl.adams@port.ac.uk

Ali El-Zaart, Faculty of Science, Department of Mathematics and Computer Science, Beirut Arab University, Beirut, Lebanon E-mail: elzaart@bau.edu.lb

Published by/ Publicado por: TECSI FEA USP - 2015 All rights reserved. 
intelligent and sustainable; through the life style they have, the knowledge infrastructure of the city and the technologies they use. As a result, many people are moving to live in cities.

According to the United Nations' World Urbanization Prospects report of year 2014, more people are living in urban areas than in rural areas, with more than $50 \%$ of the world's population residing in urban areas at the end of 2014 . In 1950 , only $30 \%$ of the world's population was urban, while by $2050,70 \%$ of the world's population is expected to be urban as illustrated in Figure 1 (UN, 2014).

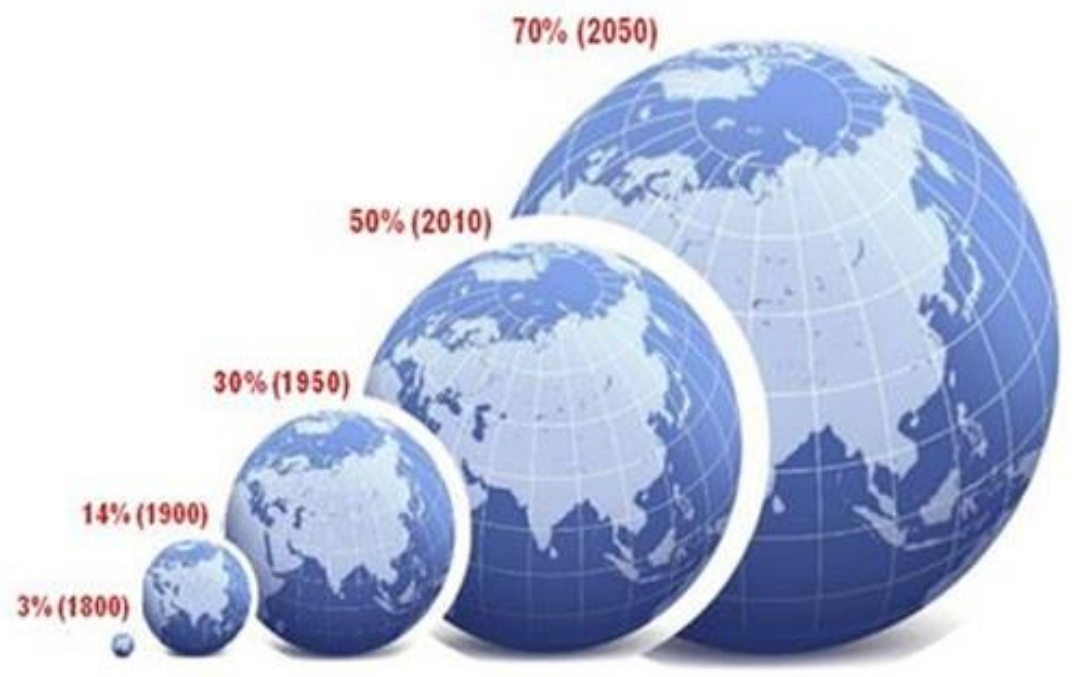

\section{Figure 1: The rapid urbanization of cities from year 1800 to 2050}

The rapid urbanization affects sustainability of cities and adds a set of challenges at the city level including poverty expansion, social stress, urban pollution and natural resources shortage. This, in turn, increases demands for economic, social, environmental and technological development especially in the lower-middle-income countries where the speed of urbanization is fast. To ensure sustainability; each city needs to adopt solutions to face the rapid urbanization phenomenon in an effective way (Harrison \& Donnelly, 2011). As a result, many governments in cities and other parties are currently initiating Smart Sustainable City (SSC) projects with the aim of addressing the rapid urbanization's challenges. The five developments that form the seeds of the SSCs concept are the globalization of environmental problems and sustainable development; urbanization and urban growth; sustainable urban development and sustainable cities; Information and Communication Technologies (ICT); and smart cities (Höjer\&Wangel, 2014).

Cities become smarter when government, business and communities increasingly rely on ICT technologies with a view of overcoming the challenges of the rapid urbanization (Washburn \&Sindhu, 2011). Building a sustainable city, in turn, requires investment at different levels including renewable energy sources; efficient use of water and electricity; fast, reliable and affordable public transportation; resources to support green technology transfer; and others (UN, 2013). Therefore, cities can be sustainable without being smart and can be smart without being sustainable. In other words, cities can be made sustainable without the use of smart ICT technologies and smart technologies can also be used within cities without giving a share in the 
sustainable development (Höjer\&Wangel, 2014). Thus, the adoption of SSCs solutions requires the use of smart ICT technologies to make cities more sustainable.

According to the International Telecommunication Union's Focus Group on Smart Sustainable Cities (ITU-T FG-SSC), a SSC is an "innovative city that uses information and communication technologies (ICTs) and other means to improve quality of life, efficiency of urban operation and services, and competitiveness, while ensuring that it meets the needs of present and future generations with respect to economic, social and environmental aspects". Additionally, a SSC is a city to be defined along six dimensions named Smart Economy, Smart Governance, Smart People, Smart Environment, Smart Mobility and Smart Living (ITU-T FG-SSC, 2014).

Recently, many governments around the globe have announced SSC initiatives. Cities from the European Union, USA, Japan, China, Korea and others have initiated many city-based projects to target the issue. Consequently, some Arab countries have announced large and medium scale SSC initiatives. The latter includes, but not limited, to King Abdullah Economic City in Saudi Arabia, Lusail City in Qatar, Masdar City in the United Arab Emirates, Rabat City in Morocco, Smart Village in Egypt and Tunisia Economic City in Tunisia (Ibrahim et al, 2015). In contrast, many other cities in the region are still suffering from a knowledge gap in relation to the transformation towards SSCs due to a set of constrains that exist at a country and/or a city level. These constraints range from the socio-economic inequality and political instability to inappropriate ICT infrastructure and lack of well-managed transportation network (Ibrahim et al, 2015).

In order to adopt SSC solutions, a structured framework to guide the transformation process is needed. The framework must address all dimensions of a SSC. It should fully describe a process that will help key stakeholders and city/community participants to understand how cities operate; define city objectives and stakeholder roles; and understand the role of ICT within physical city assets (CISCO, 2012). A SSC framework enables both the public and private sectors to plan and implement SSC initiatives more effectively. It will not only enable efficiencies in city infrastructures, but also transparencies into how cities work.

This research takes a transformation perspective on SSC. It evaluates existing frameworks for the transformation towards SSCs, and uses examples of SSCs initiatives within the Arab region. The research further identifies the two main emergent approaches to SSCs named Greenfield and Brownfield approaches. Additionally, the challenges facing the transformation process in the Arab region are not well covered in the literature. Therefore, the challenges facing the sustainable development in the region in addition to the challenges facing specific SSC initiatives in the region were intensively collected and analyzed to come up with a general set of challenges facing the transformation towards SSCs in the Arab region.

In what follows, the research objectives, justifications and questions are highlighted in sections 2, 3 and 4 respectively. Section 5 sheds light on the used research method. The literature review on a SSC's definition, dimensions, the emergence of the two main approaches to SSCs and some of existing SSC transformation frameworks are discussed out in section 6. Section 7 highlights the challenges facing the transformation process in the Arab region followed by examples of SSCs initiatives within the region. The paper concludes by discussing the results, recommendations and limitations of the proposed research. 


\section{OBJECTIVES}

A significant challenge for policy makers is how to achieve successful transformation towards SSC to enable cites to cope with growing population and sustainably manage resources. One area that is not well covered in the literature is the application of SSC within specific regions, such as the Arab region. The objectives of this research could be summarized as follows:

1. Conduct a literature review on definition and dimensions of a SSC concept.

2. Identify the Greenfieldand Brownfield approaches of SSCs transformation.

3. Provide examples of existing SSCs initiatives and transformation frameworks.

4. Identify the challenges of achieving SSCs projects across the Arab region.

5. Shed light on a knowledge gap in relation to the transformation towards SSCs in the Arab region.

\section{JUSTIFICATION}

The research is about evaluating existing frameworks for the transformation towards SSCs, and uses examples of SSCs initiatives within the Arab region to identify some of the challenges to achieve both smart and sustainable transformation within the region. These challenges could form the bases to identify the knowledge gap in relation to the transformation towards SSCs between the Arab region and other parts of the globe. The research further identifies two main emergent approaches to SSCs, those being Greenfield and Brownfield approaches. It will also demonstrate how the transformation process varies from one city to another according to the city needs.

\section{QUESTION}

Different cities around the globe are currently initiating SSC projects with the aim of addressing the rapid urbanization and globalization challenges. However, many countries and cities in the Arab region are still suffering from a knowledge gap in relation to transformation towards SSCs. In this research, the idea is to identify a set of significant challenges facing the transformation process in the Arab region by answering the research question of "Is the Arab region ready for the transformation toward SSCs yet?" By answering this question, the research will show the importance of closing the identified transformation knowledge gap in the Arab region for the purpose of enabling cites to cope with growing population and sustainably manage their resources.

\section{RESEARCH METHOD}

To answer the research question of identifying the readiness of the Arab region to transform toward SSCs, the research went through various phases. Initially, a literature review on the definition and dimensions of a SSC was conducted. Then, the research evaluated existing frameworks for the transformation towards SSCs, and listed examples of SSCs initiatives from the Arab region. It also identified two main emergent approaches to SSCs, namely Greenfield and Brownfield approaches. Finally, in order to identify the challenges facing the transformation towards SSCs in the Arab region, which are not well covered in the literature, this paper addresses the challenges facing sustainable development in the Arab region in addition those facing specific SSC initiatives in the region. The result of the latter is a general set of challenges facing the transformation toward SSCs in the Arab region. By doing so, the research discussed several questions related to the identification of a knowledge gap in relation to transformation towards SSCs in the Arab region. 


\section{LITERATURE REVIEW}

The challenges and opportunities of increasing urbanization and the rise of cities as the nexus of economic, social and technological development stimulated governments around the globe to take strategic responses to address these challenges. This section addresses some of the available definitions and dimensions of SSCs in the literature. The emergence of the two main approaches to SSCs is puzzled out in addition to examples of SSCs initiatives and existing SSC transformation frameworks. The challenges facing the transformation towards SSCs in the Arab region and a knowledge gap in relation to transformation toward SSCs will be also highlighted.

\subsection{SSC Definition and Dimensions}

The concept of SSC is recent; therefore; the work on defining and conceptualizing it is still in progress with a lack of agreement on its definition (ITU-T FG-SSC, 2014). A SSC is an aggregate notion in which each of the constituent concepts, namely smart, sustainable and city, is important in its own right. Thus, an entity is qualified as a SSC if all three parts are presented. If not, then the entity is instead a sustainable city, a smart city, a case of sustainable city or something else (Höjer\&Wangel, 2014).

From a sustainability perspective, the use of ICTs is not a must as long as the city is sustainable, thus the concept of a sustainable city becomes sufficient. From an ICT perspective, as long as smart solutions are considered, then the concept of sustainability is not on the priority list, thus the concept of a smart city becomes sufficient. However, from a comprehensive perspective, as illustrated in Figure 2 , the concept of SSCs is needed.

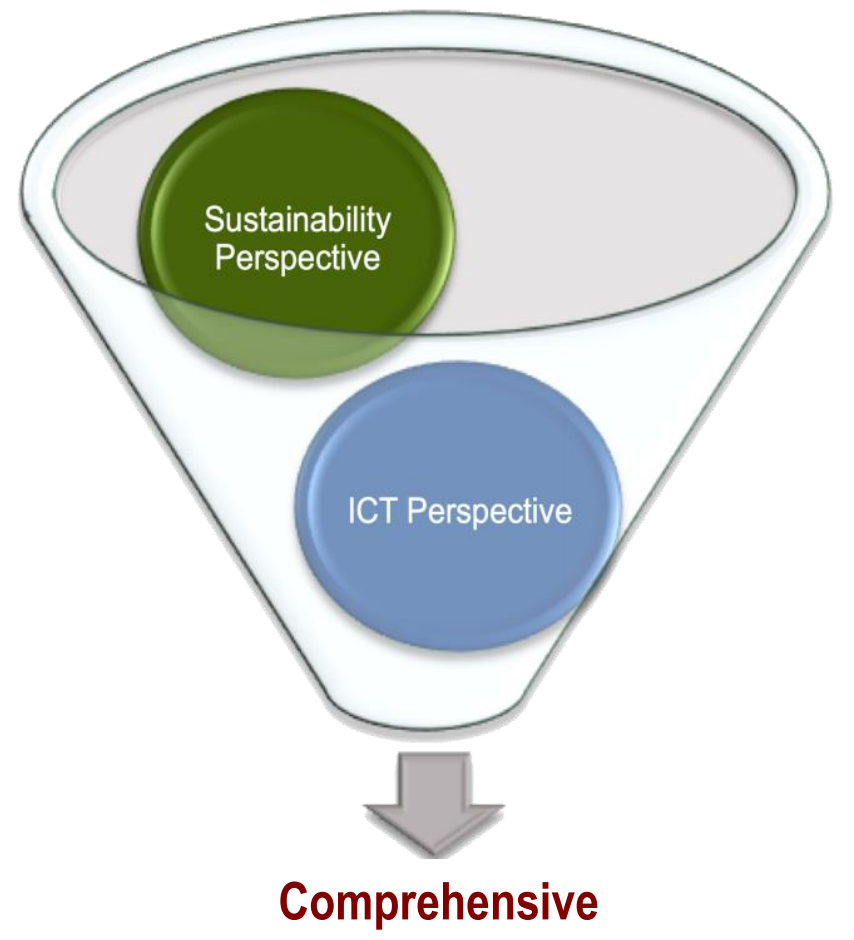

Perspective - SSC

Figure 2: A SSC as a comprehensive solution

JISTEM, Brazil Vol. 12, No. 3, Sept/Dec., 2015 pp. 559-576 www.jistem.fea.usp.br (ळc) EY 
Accordingly, several working definitions on the concept of a SSC have been put in practical and academic use. Cohen (2011) defines SSCs as cities that use ICT technologies to be more intelligent and efficient in the use of resources, resulting in cost and energy savings; improved service delivery and quality of life; and reduced environmental footprint.

The European Parliament (2014) denotes that a SSC must provide ICT-based solutions to address public issues as well as to improve competitiveness to ensure a more sustainable future of the city. According to the British Standards Institutions (BSI, 2014), a SSC must deliver a sustainable, prosperous and inclusive future for its citizens through an effective integration of its digital, physical and human systems.

The International Telecommunication Union Focus Group on Smart Sustainable Cities (ITU-T FG-SSC, 2014) provides a stupendous definition of a SSC. After analyzing approximately 116 existing definitions of a SSC in the literature and extracting and analyzing the top keywords and characteristics that make a SSC, the ITU-T FG-SSC introduces a comprehensive definition for a SSC. The definition reads as follows "A SSC is an innovative city that uses ICT technologies and other means to improve quality of life, efficiency of urban operation and services, and competitiveness, while ensuring that it meets the needs of present and future generations with respect to economic, social and environmental aspects".

Last but not least, in (Höjer and Wangel, 2014) a SSC is a city that meets the needs of its present inhabitants, without compromising the ability for other people or future generations to meet their needs; a thus, not exceeding local or planetary environmental limitations, and where this is supported by ICT.

In addition to the definitions mentioned above, Table 1 illustrates a selected set of existing definitions of SSCs. The table clarify that a SSC concept is no longer limited to the diffusion of ICT, but rather it looks at community and people needs as well as the need of a sustainable development within the city.

In relation to SSCs dimensions, Giffinger et al. (2007) identify six dimensions named: Smart Economy, Smart Mobility, Smart Environment, Smart Governance, Smart People and Smart Living. Researchers such as (Soom, 2009; Girard et al., 2009; Cohen, 2010; Khansari et al., 2013; EP, 2014; ITU-T FG-SSC, 2014; IEEE, 2015) have agreed on these dimensions and based their research and proposed transformation frameworks on them. 
Table 1: Selected Definitions of a SSC Concept

\begin{tabular}{|l|l|}
\hline \multicolumn{1}{|c|}{ Definition } & Source \\
\hline $\begin{array}{l}\text { A city is smart when investments in human and social capital } \\
\text { and traditional (transport) and modern (ICT) communication } \\
\text { infrastructure fuel sustainable economic growth and a high } \\
\text { quality of life, with a wise management of natural resources, } \\
\text { through participatory governance. }\end{array}$ & \\
\hline $\begin{array}{l}\text { A Smart Sustainable City is an urbanized area where multiple } \\
\text { public and private sectors cooperate to achieve sustainable }\end{array}$ & Gartner \\
outcomes through the analysis of contextual information \\
exchanged between them. The sectors could include hospitals \\
or emergency services or finance and so on. The interaction \\
between sector-specific and intra-sector information flows \\
results in more resource-efficient cities that enable more \\
sustainable citizen services and more knowledge transfer \\
between sectors.
\end{tabular}


A Smart Sustainable City is a developed urban area that creates sustainable economic development and high quality of life by excelling in multiple key areas: economy, mobility, environment, people, living, and government. Excelling in these key areas can be done through strong human capital, social capital, and/or ICT infrastructure.

A 'Smart Sustainable City' is one that dramatically increases the pace at which it improves its social economic and environmental (sustainability) outcomes, responding to challenges such as climate change, rapid population growth, and political and economic instability by fundamentally improving how it engages society, how it applies collaborative leadership methods, how it works across disciplines and city systems, and how it uses data information and modern technologies, in order to provide better services and quality of life to those in and involved with the city now and for the foreseeable future.

Business
Dictionary (2014)
ISO/IEC
(2015)

\subsection{Transformation towards Smart Sustainable Cities}

Nowadays, rapid urbanization is making the move towards SSCs a must. Many corporations, in turn, have proposed frameworks to support the transformation process. This includes but not limited to CISCO (CISCO, 2012), IBM (Paroutis et al., 2014), Panasonic (Hinton et al., 2014), and Huawei (Huawei, 2014). Consequently, many governments in cities around the globe; including cities in the European Union (EPIC, 2013), United Kingdom (PAS, 2014), China (Lee \& Hancock, 2014), and USA (Clarke, 2013); established their own frameworks to address the issue.

In the Arab region, some countries announced large and medium scale SSC initiatives. The latter includes but not limited to King Abdullah Economic City in Saudi Arabia, Lusail City in Qatar, Masdar City in the United Arab Emirates, Rabat City in Morocco, Smart Village in Egypt, Tunisia Economic City in Tunisia and Kuwait city in Kuwait (Ibrahim et al, 2015). In contrast, many other cities in the region are still suffering from a knowledge gap in relation to the transformation towards SSCs due to a set of constraints that exist at a country and/or a city level. These constraints range from the socio-economic inequality and political instability to the inappropriate ICT infrastructure and lack of well-managed transportation network (Ibrahim et al, 2015).

The SSC frameworks, as illustrated in Figure 3, are divided into two models named the Greenfield model, by which cities are created from scratch, and the Brownfield model, which is applied to existing cities (Amitrano, 2014). An example of the former is Masdar City in the United Arab Emirates, which will be built, by the year 2020, just a few kilometers from the center of Abu Dhabi and only 15 kilometers from Dubai. Further, Amsterdam represents one of the most known examples of the Brownfield model. The city started to offer innovative solutions in terms of sustainable mobility, energy efficiency and urban requalification (Ambrosetti, 2012). It is important to note that Greenfield cities require large investments in ICT technologies for the 
development of new constructions; however; Brownfield cities require an evolution or transformation of existing ICT capabilities.

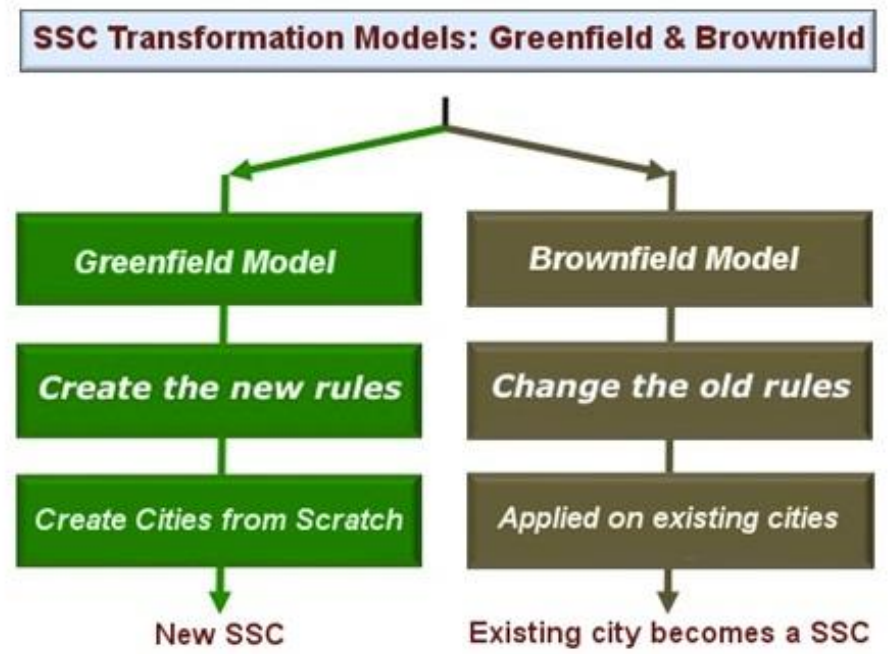

\section{Figure 3: Greenfield versus Brownfield SSCs}

Regardless of the used model; Greenfield or Brownfield model; all existing frameworks in the literature divide the transformation process into phases, which in turn are divided into sub-phases. The most common phases between these frameworks are named: planning phase, initiate phase, design phase, deliver phase, consolidate phase and transform and operate phase. However, the proposed sub-phases vary from one framework to another. For example, the main phases of a framework could be divided into a set of sub-phases including the development of a SSC strategy and business cases; improvement of economic, social and environmental pillars; enhancement of city's network infrastructure; and provision of e-services to citizens (CISCO, 2012 \& EPIC, 2013).

Each existing transformation framework deals with the transformation process from its point of view based on the needs and characteristics of the city over which it will be applied. Following are selected examples of existing transformation frameworks toward SSCs.

\subsubsection{European Platform for Intelligent Cities Framework}

The European Platform for Intelligent Cities (EPIC, 2013) proposes a SSC transformation framework/roadmap that provides a deployment guide indicating how a SSC can transform and evolve services (e.g. e-Government services) and deliver them through the EPIC platform. Six phases are identified for the EPIC framework to help cities to develop a SSC vision, define concrete project plans, implement SSC solutions (i.e. design, build and deliver) and operate SSC services in a cloud environment. The phases, as illustrated in Figure 4, could be summarized as below:

- Vision phase: develop SSC strategy and business cases.

- Plan phase: develop the project plans and quality objectives.

- Design phase: gather business requirements and design SSC services.

- Build phase: implement and test SSC services.

- Deliver phase: prepare business transition for SSC services. 
- Operate phase: actual operation and support of SSC services.

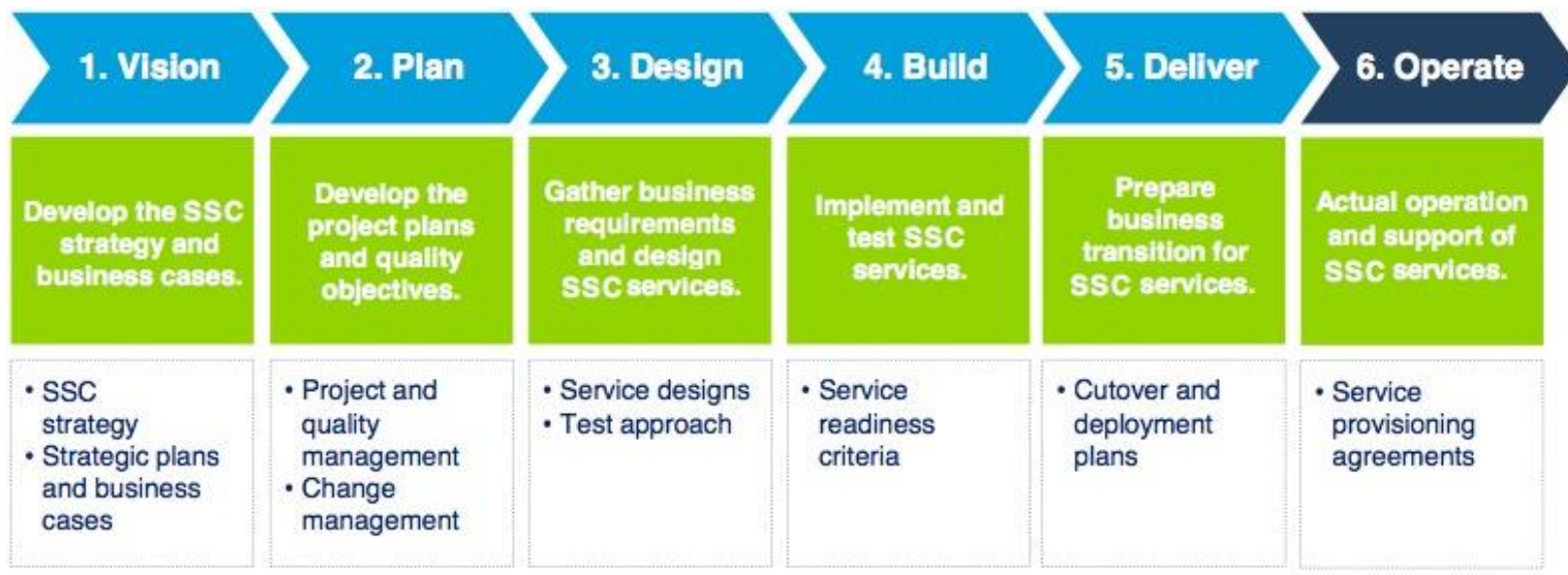

Figure 4: EPIC transformation framework towards SSCs

\subsubsection{IDC Government Insights Framework}

The International Data Corporation (IDC) Government Insights (2013) creates a SSC Maturity framework to help cities assess their current situation and determine critical capabilities needed to enable a SSC. City leaders will be able to use the proposed framework as a tool to develop a common language; improve intra- and intergroup collaboration in defining and executing a SSC strategy; and promote and encourage the use of SSC solutions. The framework identifies the phases, key measures, results and actions that are required for cities to effectively move toward a SSC. The transformation framework consists of five phases as below (Clarke, 2013):

- Ad Hoc phase: identify the traditional government modus operandi with ad hoc projects, department-based planning and discrete smart projects. The objective of the Ad Hoc phase is to begin to prove the value of the SSC concept and develop the business case.

- Opportunistic phase: the goal of this phase is to engage key stakeholders and get their buy-in as the strategy and roadmap for SSC initiatives are developed.

- Repeatable phase: identify recurring projects, events and processes for integration. The aim of this phase is to improve outcomes and service delivery as a result of repeatable processes for SSC projects.

- Managed phase: prepare city to be able to predict the needs of its residents, visitors and businesses and provide preventative services before problems arise.

- Optimized phase: a sustainable citywide platform is in place. The goal of this phase is competitive differentiation that derives the sustainable economic development of the city by creating jobs and attracting investment.

\subsubsection{British Standards Institution Framework}

The British Standards Institution (BSI) and the British Department of Business, Innovation and Skills (BIS) develop a transformation framework to facilitate the transformation process towards SSCs in Britain cities. The proposed framework, as illustrated in Figure 5, consists of four components at its top-level named: (A) guidance 
principles, (B) key cross-city governance and delivery processes, $(\mathrm{C})$ benefit realization strategy, and (D) critical success factors. On another hand, the framework further divides the SSC roadmap into a set of phases that could be summarized as below (PAS, 2014):

- Plan phase: to ensure that the business case is fully articulated and all key stakeholders are on board, a planning is needed to develop a tailored roadmap for the city. The key output of this phase includes the guiding principles, city vision, benefit realization framework and SSC roadmap.

- Initiate phase: in this first phase of delivery, the focus is on maximizing the benefits and minimizing the delivery risks. This means focusing in particular on the quick wins to demonstrate progress and early benefits; and embedding the roadmap in governance structures and processes.

- Deliver phase: during this phase, some of the more significant investments start coming on stream. For example, the first wave of smart services and applications.

- Consolidate phase: a longer term strategic solutions will be developed to focus shifts towards driving take-up of the initial SSC services and applications, learning from smart data and user feedback, and using that feedback to specify changes to the business and technology architectures.

- Transform phase: this phase includes building out the broader range of SSC projects and complete the transition to the full strategic IT platform to guarantee future agility as business and customer priorities change.

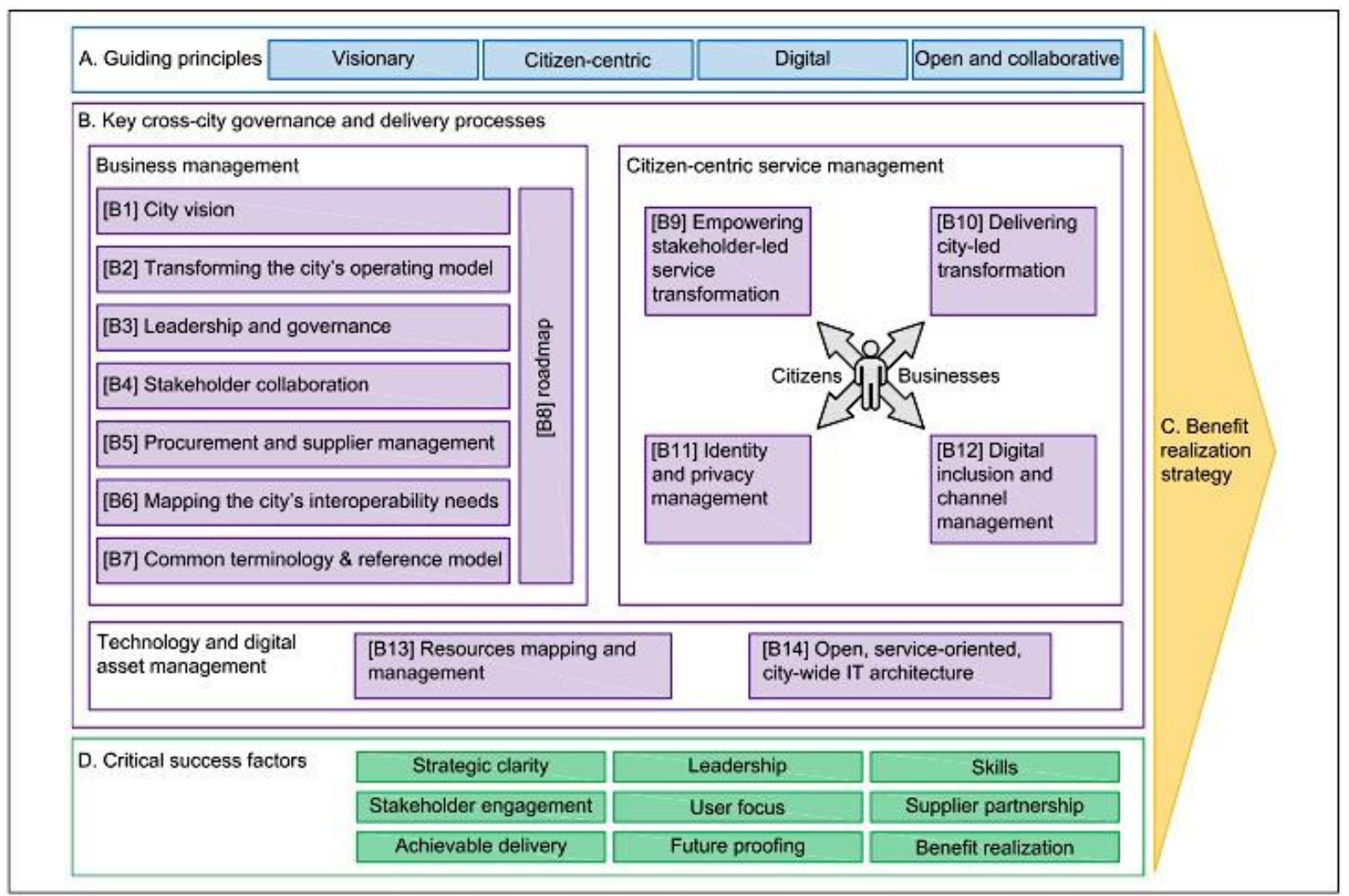

Figure 5: The BSI high-level structure of the SSC framework

\subsubsection{Masdar City Development Framework}


Masdar City in the United Arab Emirates is a model of a smart and sustainable urban development. It will be built, by the year 2020, just a few kilometers from the center of Abu Dhabi and only 15 kilometers from Dubai. The city is planned to provide an innovative working environment and high quality of life for its citizens with the least negative impact on the environment (Manghnani et al., 2014). The development framework of Masdar city is designed to achieve the client's needs by (Masdar, 2014):

- Identifying and planning for recoverable resources such as salts and bio-fuels.

- Identifying cost efficiencies for infrastructure investments to meet sustainability goals.

- Simulating water, waste and energy resource systems, including interactions such as power consumption of water desalination facilities.

- Developing Technology Roadmap Assessments including various groundwaterrelated projects, geothermal studies and waste-handling and management initiatives.

- Integrating a variety of possible technologies in a holistic analysis, such as different photovoltaic technologies for distributed power generation.

In sum, many frameworks exist in the literature to guide the transformation towards SSCs; however; each framework deals with the dimensions of a SSC in different ways and each one is being designed to meet the needs and characteristics of the city to which it will be applied. Moreover, despite the differences in the name of the various phases of the identified frameworks, commonality in the goals of these phases is noted. For example, the identified frameworks agreed on the importance of planning phase. They all named it as a "Plan Phase" except IDC framework in which it is named as "Ad Hoc Phase". Therefore, the necessity of a conceptual framework to set out a holistic view of a SSC becomes a must. The latter should consider all phases needed to transform a city into a SSC.

\section{TRANSFORMATION INITIATIVES AND CHALLENGES}

\subsection{Challenges facing SSCs Transformation: Case of the Arab Region}

Generally, the transformation towards SSC faces a set of challenges that vary from one region to another and between countries within the same region. The challenges range from economic and social to technological and regulatory. Arab countries, in turn, suffer in varied degrees from this set of challenges. The latter includes (EP, 2014; Ibrahim et al., 2015):

- Complexity challenges: SSCs require creation of a sustainable system of systems capable of generating opportunities for cities and their citizens.

- Economic challenges: a need for a sustainable financial investment to support a SSC projects, which is highly dependent on the economic status of a country, thereby a city.

- Social challenges: the necessity to adopt SSC services to the specific needs of each user (i.e. citizen).

- Governance challenges: the need of coordination and integration between public, private and civil bodies for the purpose of making a city function as one organism in an efficient and effective manner. 
- Technological challenges: this includes but not limited to the operating cost; security and privacy; lack of ICT infrastructure; technological obsolescence; and inter- and intra-system interoperability.

In addition to the above challenges, there are additional long-term challenges to SSCs development in the Arab region. Some of these challenges are strongly critical. This includes the political instability, high rate of youth unemployment, growing inflation pressures, food insecurity, lack of energy and others (Government Summit, 2015). Despite the challenges, some Arab countries start their journey towards SSCs, either by building SSCs from scratch or by adopting and applying SSCs solutions on the top of existing cities. The next section will highlight the situation of SSCs initiatives in the Arab region.

\subsection{SSC Initiatives in the Arab Region}

To face globalization challenges and the need of sustainable urban development, selected cities in the Arab region start adopting Greenfield and/or Brownfield SSCs solutions. These cities include but are not limited to Masdar City in the United Arab Emirates, Smart Village in Egypt, King Abdullah Economic City in Saudi Arabia, Tunisia Economic City in Tunisia and Rabat City in Morocco. In contrast, many Arab countries, thereby cities, are still suffering from a knowledge gap in relation to the transformation towards SSCs. This gap occurs due to a set of constraints exists at a country and/or a city level.

Table 2 summarizes the status of SSC initiatives in the Arab region (Ibrahim et al., 2015).It illustrates the type of existing initiatives, Greenfield or Brownfield, in each country in the region with an example of the existing SSC project. The dash character indicates the lack of any SSC initiative in the selected country. 
Table 2: Greenfield and Brownfield SSC Initiatives in Arab Region

\begin{tabular}{|c|c|c|c|}
\hline Country & $\begin{array}{l}\text { SSC } \\
\text { Initiatives }\end{array}$ & Brownfield/Greenfield & Example of a SSC Project \\
\hline Algeria & Yes & Greenfield & $\begin{array}{lll}\text { Cyberpark } & \text { City } & \text { of } \\
\text { SidiAbdellah } & & \end{array}$ \\
\hline Bahrain & Yes & Brownfield & Manama \\
\hline Comoros & No & - & - \\
\hline Djibouti & No & - & - \\
\hline Egypt & Yes & Greenfield & Smart Village \\
\hline Iraq & No & - & - \\
\hline Jordan & No & - & - \\
\hline Kuwait & Yes & Brownfield & Kuwait City \\
\hline Lebanon & No & - & - \\
\hline Libya & No & - & - \\
\hline Mauritania & No & - & - \\
\hline Morocco & Yes & Brownfield & Rabat \\
\hline Oman & Yes & Brownfield & Masqat \\
\hline Palestine & No & - & - \\
\hline Qatar & Yes & Brownfield/ Greenfield & $\begin{array}{l}\text { Lusail City - Greenfield } \\
\text { Doha City - Brownfield }\end{array}$ \\
\hline Saudi Arabia & Yes & Greenfield & $\begin{array}{l}\text { King Abdullah Economic } \\
\text { City }\end{array}$ \\
\hline Somalia & No & - & - \\
\hline Sudan & No & - & - \\
\hline Syria & No & - & - \\
\hline Tunisia & Yes & Greenfield & $\begin{array}{l}\text { Tunisia Economic City (in } \\
\text { planning stage) }\end{array}$ \\
\hline $\begin{array}{l}\text { United Arab } \\
\text { Emirates }\end{array}$ & Yes & Brownfield/ Greenfield & $\begin{array}{l}\text { Masdar City - Greenfield } \\
\text { Dubai City - Brownfield }\end{array}$ \\
\hline Yemen & No & - & - \\
\hline
\end{tabular}




\section{RESULTS}

One area that is not well covered in the literature is the application of SSC within specific regions, in specific, the Arab region in addition to the challenges facing the transformation process. The proposed research evaluates existing frameworks for the transformation towards SSCs, and uses examples of SSCs initiatives within the Arab region. It further identifies two main emergent approaches to SSCs named Greenfield and Brownfield approaches. Last but not least, the proposed research highlights a knowledge gap in relation to transformation towards SSCs in the Arab region; caused by a set of constraints that exists at a country and/or a city level. The latter includes, but not limited to, the socio-economic inequality, inappropriate ICT infrastructure, unstable political situations, lack of developed and well-managed transportation networks and unemployment youth.

\section{CONCLUSION}

Rapid urbanization and globalization make the move towards SSCs a must. As a result, many cities around the globe start their move toward SSCs, including selected cities in the Arab region that are ready for the transformation process. However, many others are still suffering from a knowledge gap in relation to transformation towards SSCs; due to a set of constraints that exists at a country and/or a city level. The suggested future research is a development of a comprehensive transformation framework toward SSCs that can be customized to meet the characteristics of each city to which it will be applied while keeping an eye on the identified challenges facing the transformation process in the Arab region.

\section{RECOMMENDATIONS AND LIMITATIONS}

The proposed method of identifying the challenges facing the transformation towards SSCs in the Arab region as well as highlighting a knowledge gap in the subject matter is recommended. The latter would form the basis for creating a transformation framework that can be customized to the development level of Arab countries, thereby cities, and their readiness for change. The framework would help closing the knowledge gap in relation to the transformation towards SSCs in the region.

One of the limitations faced in the proposed research was the lack of resource for the used transformation frameworks toward SSCs in the Arab region. There is scarce literature review on the subject matter. On another note, the challenges facing the transformation process in the region are not well covered in the literature. To overcome this problem, the challenges facing the sustainable development in the Arab region in addition to the challenges facing specific SSC initiatives in the region were intensively collected and analyzed to come up with a general set of challenges.

\section{REFERENCES}

Ambrosetti (2012).Smart Cities in Italy: an Opportunity in the Spirit of the Renaissance for New Quality of Life. The European House - Ambrosetti for ABB.

Amitrano, C. (2014). New Smart Cities: a Focus on Some Ongoing Projects. Proceedings of the 3rd International Virtual Conference (ICTIC).Vol. 1, pp. 383-388. 
BSI (2014). Smart Cities - Vocabulary. British Standards Institute (BSI), BSI Standards Publication, PAS 180:2014. London: United Kingdom.

Bulu, M. (2014). Upgrading a city via technology. Technological Forecasting and Social Changes, Vol. 89, pp. 63-67.

Business Dictionary (2014). Smart City. Business Dictionary. Web. Accessed, Retrieved from:http://www.businessdictionary.com/definition/smart-city.html.

Caragliu, A., Del Bo, C. \&Nijkamp, P. (2011). Smart Cities in Europe. Journal of Urban Technology, Vol.18, No. 2, pp. 65-82.

CISCO (2012).Smart City Framework - A Systematic Process for Enabling Smart+Connected Communities. Cisco Internet Business Solutions Group (IBSG): Falconer, G. \& Mitchell, S.

Clarke, R. (2013). Business Strategy: IDC Government Insights' Smart City Maturity Model - Assessment and Action on the Path to Maturity. International Data Corporation (IDC) Government Insights, Business Strategy \#GI240620. Alexandria, VA: USA.

Cohen, B. (2011). The Top 10 Smart Cities on the Planet. Fast Company. Web. Accessed, Retrieved from: http://www.fastcoexist.com/1679127/the-top-10-smartcities-on-the-planet.

Cohen, B. (2012). 6 Key Components for Smart Cities.UBM's Future Cities. Web. Accessed, Retrieved from:http://www.ubmfuturecities.com/author.asp?section_id $=219 \& \mathrm{doc} \mathrm{id}=524053$

Doherty, P. (2014). Report on Smart Cities: A New Dynamic for the Middle East. McGRAW HILL FINANCIAL, Global Institute.

EC (2013).European Innovation Partnership on Smart Cities and Communities Strategic Implementation Plan. European Commission (EC), Communications, Networks, Content and Technology Publications. Brussels: Belgium.

EP (2014).Mapping Smart Cities in the EU. European Union (EU), European Parliament's Committee on Industry, Research and Energy, Policy Department A: Economic and Scientific Policy. Brussels: Belgium.

EPIC (2013).EPIC Roadmap for Smart Cities. European Union, European Platform for Intelligent Cities (EPIC), Version 1.0, Project no. 270895.

Gartner (2011).Hyper Cycle for Smart City Technologies and Solutions. Gartner, Inc. Stamford: USA.

Giffinger, R., Fertner, C., Kramar, H., Kalasek, R., Pichler-Milanović, N. \&Meijers, E. (2007).Smart Cities - Ranking of European Medium-sized Cities. Center of Regional Science (SRF), Vienna University of Technology. Graz, AG: Austria.

Girad, L.F., Lombardi, P. \&Nijkamp, P. (2009). Creative Urban Design and Development. International Journal of Services Technology and Management, Special issue, Vol. 13, No. 2-3, pp. 111-115.

Government Summit (2015). Smart Cities: Regional Perspective. The Government Summit - Arab Region. Dubai: UAE.

Harrison, C. \& Donnelly, I. A. (2011).A Theory of Smart Cities.Proceedings of the 55th Annual Meeting of the ISSS. Hull, UK: University of Hull Business School. 
Hinton, J., Barrett, S., Eaton-Whitifield, C. \& Wilson, R. (2014). Fujisawa Sustainable Smart Town Goes Into Full-Scale Operation Near Tokyo. Panasonic, Press Release.

Höjer, H. \&Wangel, J. (2014). Smart Sustainable Cities - Definition and Challenges. ICT Innovations for Sustainably, Advanced in Intelligent Systems and Computing, Springer International Publishing, Vol. 310, pp. 333-349.

Huawei (2014). Understanding Top-Level Design for Smart Cities. Huawei Enterprise, ICT Insights, Issue 10, p. 12. Huawei: Linyi, T. \& Jun, J.

Ibrahim, M., Al-Nasrawi, S., El-Zaart, A. \& Adams, C. (2015). Challenges facing E-Government and Smart Sustainable City: An Arab Region Perspective. 15th European Conference on e-Government, ECEG, pp. 369-404.

IEEE (2015). IEEE Smart Cities. Institute of Electrical and Electronics Engineers (IEEE). Web. Accessed, Retrieved from: http://smartcities.ieee.org/about.html

ISO/IEC (2015).Smart Cities - Preliminary Report (2014).International Organization for Standardization and International Electrotechnical Commission (ISO/IEC). Genève: Switzerland.

ITU-TFG-SSC (2014).Technical Report on Smart Sustainable Cities: An analysis of definitions. United Nations, International Telecommunication Union (ITU-T), Focus Group on Smart Sustainable Cities (FG-SSC).

Khansari, N., Mostashari, A. \&Mansouri, M. (2013).Impacting Sustainable Behaviour and Planning in Smart City.International Journal of Sustainable Land use and Urban Planning, Vol. 1, No. 2, pp. 46-61.

Lee, J. \& Hancock, M. (2014). Towards an Effective Framework for Building Smart Cities: Lessons from Seoul and San Francisco. Technological Forecasting \& Social Change, Elsevier Publications, Vol. 89, pp. 80-99.

Manghnani, N. and Bajaj, K. (2014). Masdar City: A Model of Urban Environmental Sustainability.Journal of Engineering Research and Applications, Vol. 4, No. 10, pp. $38-42$.

Masdar (2014).Masdar City Sustainability Planning.CH2M HILL Company. Web Accessed, Retrieved from: http://www.ch2m.com/corporate/water/water-systemsmanagement/masdar-abu-dhabi.asp\#.VQCmcGarYsQ

Osborne, D. \&Gaebler, T. (1992). Reinventing Government. Addison-Wesley, USA: Reading.

Paroutis, S., Bennett, M. \&Heracleous, L. (2014). A Strategic View on Smart City Technology: The Case of IBM Smarter Cities during a Recession. Technological Forecasting and Social Change, Elsevier Publications, Elsevier Publications, Vol. 89, pp. 262-272.

PAS (2014).Smart city framework - Guide to establishing strategies for smart cities and communities. The British Standards Institution (BSI), Department of Business, Innovation \& Skills (BIS), BSI Standards Limited Publication (PAS 181:2014).

Soom, E.V. (2009). Measuring Levels of Supply and Demand for e-Services and e-Government: a Toolkit for Cities. The Interreg IVB North Sea Region Programme, Smart Cities Research Brief, No. 3. Brussels: Belgium. 
UN (2014).Report of the World Urbanization Prospects: the 2014 Revision, Highlights. United Nations, Department of Economic and Social Affairs, Publication Division (ST/ESA/SER.A/352).

UN (2013).Survey on the Sustainable Development Challenges. United Nations, Department of Economic and Social Affairs, Publication Division (ST/ESA/344).

UN-GC. (2013). Urban Profile Process - Circles of Sustainability. United Nations Global Compact (UN-GC), Global Compact Programme, Version 3.3.

Washburn, D. \&Sindhu, U. (2011). Helping CIOs Understand "Smart City" Initiatives: Defining the Smart City, Its Drivers, and the Role of the CIO. Cambridge, MA: Forrester Research, Inc. 